\title{
Determinants of Suicidal Behaviour in Malaysia
}

\author{
Yong Kang Cheah ${ }^{\mathrm{a}}$ \\ Universiti Utara Malaysia \\ Mohd Azahadi ${ }^{\mathrm{b}}$ \\ Institute for Public Health \\ Siew Nooi Phang \\ Universiti Utara Malaysia \\ Noor Hazilah Abd Manaf ${ }^{d}$ \\ International Islamic University Malaysia
}

\begin{abstract}
A sharp rise in the prevalence of suicide has become a serious public health concern. Acquiring a better understanding of the determinants of suicidal behaviour can help to implement a more effective policy directed towards reducing the suicide rate. In this study, we attempt to examine the effects of sociodemographic, lifestyle and health factors on suicidal behaviour among Malaysian adults. A rigorous statistical method and a nationally representative data are used for analyses. We find that age, gender, race, marital status, self-rated health, diabetes and hypercholesterolemia are significantly associated with suicidal behaviour. Specifically, there are positive relationships between the likelihoods of engaging in suicidal behaviour and young adults, females, Indians/others, being unmarried, and having poor health conditions. We conclude that sociodemographic and health factors play an important role in affecting suicidal behaviour, whereas lifestyle factor does not. As an intervention measure towards overcoming the problem of high suicide rate, effective policies should be targeted at individuals who are likely to engage in suicidal behaviour.
\end{abstract}

Keywords: Age, health, marital status, race, suicide

JEL classification: D12, I12

a School of Economics, Finance and Banking, College of Business, Universiti Utara Malaysia, 06010 UUM Sintok, Kedah Darul Aman, Malaysia. Email: yong@uum.edu.my, cheahykang@gmail.com (Corresponding author)

b Centre for Burden of Disease Research, Institute for Public Health, Ministry of Health Malaysia, Jalan Bangsar, 50590 Kuala Lumpur, Malaysia. Email: drazahadi@moh.gov.my

c School of Government, College of Law, Government and International Studies, Universiti Utara Malaysia, 06010 UUM Sintok, Kedah Darul Aman, Malaysia. Email: siewnooi@uum.edu.my

d Department of Business Administration, Faculty of Economics and Management Sciences, International Islamic University Malaysia, 50728 Kuala Lumpur, Malaysia. Email: hazilah@iium.edu.my

* The authors would like to thank the Director General of Health, Malaysia for permission to use data from the National Health and Morbidity Survey 2011 and to publish this paper. Research support from the Universiti Utara Malaysia (Research Generation University Grant) is gratefully acknowledged (KOD SO 13892).

Article Info: Received 27 August 2017; Revised 6 May 2018; Accepted 17 August 2018

https://doi.org/10.22452/MJES.vol55no2.5 


\section{Introduction}

In today's society, more and more people use suicide as a method to escape stress. As a result, there is a sharp rise in the suicide rate. Every year, almost one million people commit suicide (World Health Organization, 2016). This alarming figure has raised the concern of public health administrators. Suicide is also one of the main causes of death among young adults (15-29 years) (World Health Organization, 2016). The negative consequences of suicide on society are numerous. It is well documented that stress of an individual can be elevated if he/she loses his/her loved ones to suicide. Suicide can also hinder economic growth because it causes a reduction in human capital (Ying \& Chang, 2009). As pointed out in the study, there is a negative association between gross domestic production (GDP) and suicide rate (Ying \& Chang, 2009).

The suicide rate in Malaysia is one of the highest in South East Asia, which is responsible for an estimated 13.1 deaths per 100,000 population (Hendin et al., 2008). This figure is, however, underreported because suicide is illegal in Malaysia and is unaccepted by Islam, that is, the official religion in Malaysia. While the suicide rate in Malaysia is not as serious as those of other countries in Asia, such as Sri Lanka, Japan and South Korea, it should be given special attention. The evidence shows that more than one thousand of suicide cases were recorded in Malaysia from 2007 to 2010 (Sipalan, 2012; Sunip, 2015). Worse still, this figure is anticipated to increase in the near future. In terms of suicidal behaviour, a previous study showed that, in 2011, 1.7 percent, 0.9 percent and 0.5 percent of adults had suicidal ideation, suicide plan and suicide attempt, respectively (Institute for Public Health, 2011).

In view of the sharp rise in suicide rate, there is a growing study that examines the factors affecting suicidal behaviour in various countries. These include the United States (Neumayer, 2003b; Purselle, Heninger, Hanzlick, \& Garlow, 2009; Rehkopf \& Buka, 2006), Denmark (Qin, Agerbo, \& Mortensen, 2003), Eastern Europe (Kolves, Milner, \& Varnik, 2013), China (Li, Li, \& Cao, 2012), Korea (Song \& Lee, 2016), Taiwan (Ying \& Chang, 2009) and others (Li, Page, Martin, \& Taylor, 2011). However, similar studies that are conducted in Malaysia are still lacking. Aishvarya, Maniam, Sidi and Oei (2014) and Bahar et al. (2015) are among the few researchers that focus on suicidal behaviour in Malaysia, but their scopes are limited to hospital patients and youths. As such, their results cannot represent the entire population. Aishvarya et al. (2014) who reviewed previous studies pertaining to suicide ideation found that the prevalence of suicide ideation varied across sociodemographic factors. Bahar et al. (2015) used a cross-sectional data and identified that the majority of the youths who committed suicide were males and Indians. However, these researchers did not examine the determinants of suicidal behaviour in great detail. Our objective is to narrow these research gaps by offering a more in-depth analysis of the determinants of suicidal behaviour in Malaysia. We use a nationally representative data that consists of a large sample size for investigation. Hence, our findings will have significant contributions to literature and policy development.

\section{Theoretical Basis}

According to the theory developed by Klonsky and May (2015), the decision of people to commit suicide can be explained by three steps. First, people must feel pain and 
hopelessness in order to have suicidal ideation. These individuals feel being punished by living in pain. Pain is caused by several factors, such as social isolation, negative selfperceptions and absence of sense of belonging. The greater the pain, the lower the tendency to live. Individuals feel hopeless if they do not have hope that the pain can be reduced. Hence, hopelessness causes one to think about suicide in addition to pain. Put differently, individuals who feel pain but do not feel hopeless may not think about suicide, vice versa. Second, connectedness determines suicidal ideation. Connectedness refers to individuals' closeness to their family, friends and job. Although individuals feel pain and hopeless, they may not have suicidal ideation if they have strong connectedness. In other words, if connectedness is stronger than pain and hopelessness, the individuals may not think about suicide. However, if connectedness is missing or weaker than pain and hopelessness, the individuals are likely to think about suicide.

Third, suicide attempt is affected by three factors of suicide capacity: dispositional, acquired and practical. Dispositional capacity is closely related to genetics. For example, individuals who are born with low pain thresholds are more likely to attempt suicide than individuals who are born with high pain thresholds. Another example is that individuals who have blood phobia are less likely to attempt suicide than individuals who do not have similar phobia. Acquired capacity means individuals' adaption to pain. This adaption is determined by the life experiences. Individuals who adapt to pain over time are likely to attempt suicide. Practical capacity refers to the factors facilitating suicide. For instance, individuals who have the skill of using pistol or knowledge of using poison are more likely to attempt suicide than individuals who do not have the same skill and knowledge. This means that individuals who know how to end their life easily are more likely to commit suicide than individuals who do not have this knowledge. Taken together, one can conclude that from suicide ideation to suicide attempt involves three steps, and individuals who can avoid being trapped in any of these steps are unlikely to commit suicide.

\section{Literature Review}

Based on the three-step theory of Klonsky and May (2015), we hypothesise that individuals with different sociodemographic and health profiles may have different likelihoods of taking each of the steps of suicide (pain and hopelessness, connectedness, suicide capacity). Furthermore, the relationships between suicidal behaviour and sociodemographic, and health factors are clearly evident in the literature. Therefore, our study mainly focuses on the effects of sociodemographic and health factors on suicidal behaviour.

The effect of income and suicidal behaviour has been well identified in past studies. Qin et al. (2003) used a longitudinal data and found that income was negatively associated with the likelihood of committing suicide, which was also shared by Neumayer (2003a) and Purselle et al. (2009). Their results showed that countries with higher income per capital had a lower suicide rate compared to countries with lower income per capital. The negative relationship between GDP per capita and suicide rate was also evidenced by Kolves et al. (2013), who focused on European countries. Two factors may explain why low income could lead to suicide. First, low income was often 
associated with social regulation and personal problems (Kolves et al., 2013; Neumayer, 2003a). Second, low income individuals tended to have poor well-being and quality of life. Based on the theory and previous findings, we hypothesise that income increases well-being and thus may reduce the pain. Thereby, higher income individuals may have a lower probability of engaging in suicidal behaviour than lower income individuals.

The association between age and suicidal behaviour appears to be consistent. As pointed out by Song and Lee (2016), older women were less likely to have suicidal ideation than younger women. Similarly, Casey et al. (2006) found a negative relationship between age and the odds of having suicidal thoughts. This was simply because younger individuals experienced more stress from job and household responsibilities than older individuals. It appears, therefore, that younger individuals may have greater pain and suicide capacity than older individuals. Hence, we expect that age is negatively associated with suicidal behaviour.

A review of past studies indicates that gender has significant impacts on suicidal behaviour. It was not surprising that women had a higher tendency to engage in suicidal behaviour than men. This was because of double burdens, i.e. the stresses of paid work and housework which women needed to bear (Neumayer, 2003a). The findings of Qin et al. (2003) showed likewise. The authors observed that females were more likely to commit suicide than males in Denmark. Interestingly, Neumayer (2003b) found a positive relationship between the number of female labour force and female suicide rate, and concluded that stresses of paid work could cause women to adopt suicidal behaviour. Based on these findings and the theory, we anticipate that women are more likely to engage in suicidal behaviour than men as they may have greater pain and suicide capacity.

The question regarding how ethnicity affects suicide has been answered by previous studies. Morris and Maniam (2001) using Malaysian data found that Indians were more likely to commit suicide than Malays and Chinese. They argued that religion and culture were the main factors that explained this outcome. The three main religions in Malaysia are Islam (Malay), Buddhism (Chinese) and Hinduism (Indian). These three religions have different views on suicide. According to Islam, Muslims are not allowed to commit suicide although they suffer from serious stresses. Suicide is illegal for them. Similarly, Buddhism educates its followers about the appropriate methods to deal with stress. It emphasises that suicide is not a solution. However, Hinduism allows its believers to commit suicide if they suffer from life difficulties and misfortunes. Therefore, our expectation is that Malays and Chinese have lower likelihoods of engaging in suicidal behaviour than Indians.

The negative relationship between education level and suicide has been identified in previous studies. Li et al. (2011) found that less-educated individuals were more likely to commit suicide than well-educated individuals. Likewise, using a Korean survey data, Song and Lee (2016) evidenced that being highly educated reduced the propensity to think about suicide. The reason was that education could promote rationality (Becker \& Murphy, 1988). Given that suicidal behaviour is irrational, individuals who have good education background are unlikely to engage in it. However, based on the theory, well-educated individuals may have greater suicide capacity than less-educated individuals because they have better practical skills and knowledge. As such, no specific relationship between education and suicidal behaviour is hypothesised. 
The influence of marital status on suicide has been well examined in the past. Neumayer (2003a) and Neumayer (2003b) provided an evidence that the prevalence of suicide reduced with marriage rate whereas increased with divorce rate. These findings were somewhat consistent with those of Song and Lee (2016). The authors observed a positive relationship between divorced/widowed marital status and participation in suicidal behaviour. Casey (2006) and Qin et al. (2003) also found that being unmarried increased the likelihood of committing suicide. The argument was quite straightforward. When individuals felt lonely and did not receive support from spouses, their stress level increased (Neumayer, 2003a). As such, married individuals are assumed to have better connectedness than unmarried individuals. We formulate a hypothesis that married individuals have a lower tendency to engage in suicidal behaviour than their unmarried counterparts.

The relationship between health factors and suicide was examined by Qin et al. (2003) and Vilhjalmsson, Kristjansdottir and Sveinbjarnardottir (1998). Utilising a bivariate regression, Vilhjalmsson et al. (1998) found that the presence of serious health illnesses increased the likelihood of having suicide ideation. Somewhat similar finding was evidenced by Qin et al. (2003). Their results showed that absence from work due to serious sicknesses was positively associated with the probability of committing suicide. This was simply because people who had poor health conditions were likely to face restriction of performing work and leisure activities, and consequently experienced more stress (Kolves et al., 2013). According to the theory, we assume that illness is positively associated with hopelessness. Put differently, individuals who suffer from illnesses have a higher likelihood of feeling hopeless than individuals who do not suffer from illnesses. As such, we anticipate that individuals who have poor health conditions are more likely to engage in suicidal behaviour than their counterparts with good health conditions.

\section{Methods}

Analyses of our study were based on secondary data. The data that we used was extracted from the National Health and Morbidity Survey 2011 (NHMS 2011) (Institute for Public Health, 2011). NHMS 2011 was a nationwide cross-sectional health survey conducted by the Ministry of Health Malaysia. The survey period was from April to July 2011. The database is nationally representative and had a large sample size and detailed information about the respondents' sociodemographic and health profiles. A twostage stratified sampling was used to collect the sample. The first stage sampling unit was based on geographically contiguous areas of the country [i.e. Enumeration Blocks (EBs)]. The second stage sampling unit was based on Living Quarters (LQs). Households residing in the selected LQs were canvassed. The inclusion criteria were adults aged 18 years or more, both genders and all ethnic groups. The exclusion criteria were nonMalaysians and institutionalised individuals (i.e. those staying at hotels, hostels and hospitals). The targeted sample size was calculated based on three criteria: 1) expected prevalence of diseases and health related problems in the population; 2) margin of error (between 0.01 and 0.05); and 3) confidence interval of 95 percent. Our analysis was based on 10,141 respondents. 
During the survey, trained staff used multi-lingual structured questionnaires to interview (face-to-face) respondents. The outcome variables of our study were severe suicidal behaviour and less severe suicidal behaviour. The suicidal behaviour measured in our study comprised suicidal ideation, suicide plan and suicide attempt. They were obtained by asking the respondents: 'Do you think about suicide?' 'Do you plan or have suicide method or plan in mind?' 'Have you attempted suicide?' The respondents who answered 'yes' to these three questions were considered to have severe suicidal behaviour. The respondents who answered 'yes' to the first and second questions, but 'no' to the third question were considered to have less severe suicidal behaviour.

In addition to suicidal behaviour, the questionnaires had numerous questions related to the respondents' sociodemographic, lifestyle and health profiles. Based on the three-step theory and findings of previous studies, the explanatory variables used in our study comprised income, age, family size, gender, ethnicity, education, marital status, physical activity, smoking, self-rated health, diabetes and hypercholesterolemia (Klonsky \& May, 2015; Kolves et al., 2013; Li et al., 2012; Neumayer, 2003b; Purselle et al., 2009; Qin et al., 2003; Rehkopf \& Buka, 2006; Song \& Lee, 2016). The respondents' monthly individual income [in Ringgit Malaysia (RM)], age (in years) and household size were all formatted as continuous variables. The ethnic variable was categorised into three categories: Malay, Chinese and Indian/others (reference group). Malay is the ethnic majority in Malaysia. Because of a small number of observations, both Indian and others were combined to form a single category. Somewhat similar to Cheah (2018), the respondents' education background was grouped into three categories: tertiary $(\geq 12$ years of schooling), secondary (7-11 years) and primary ( $<7$ years) (reference group). To facilitate comparisons, the respondents' marital status was categorised into two categories: married and unmarried (single/divorced/widowed) (reference group). This was in light of the fact that unmarried may display different suicidal behaviour from married individuals given the absence of spouses.

The respondents' physical activity level was measured by metabolic equivalents (METs). MET refers to the ratio of a respondent's metabolic rate during exercise compared to the metabolic rate when the respondent is sitting quietly (Cheah, Azahadi, Phang \& Abd Manaf, 2017). Those who achieved a minimum of $600 \mathrm{METs}$ minutes per week were considered to be physically active (World Health Organization, 2010). Otherwise, they were considered to be physically inactive (reference group). The respondents' smoking behaviour was categorised into two groups: smoker and non-smoker (including ex-smoker) (reference group). Three variables were used to measure the respondents' health condition, i.e. self-rated health, diabetes and hypercholesterolemia. The respondents' self-rated health condition was obtained by asking: 'In general, how would you rate your health?' Answers to this question were categorised into three categories: good (very good/good), fair and poor (not good/very bad) (reference group). See Cheah (2012) for further discussion on self-rated health. To determine whether or not the respondents had diabetes or hypercholesterolemia, the respondents' blood glucose and blood cholesterol profiles were assessed. Those who did not have these health risk factors were used as the reference groups for comparisons.

Two outcome variables were used in our study. For severe suicidal behaviour variable, 1 referred to the respondents who engaged in severe suicidal behaviour; 
0 otherwise. For less severe suicidal behaviour, 1 referred to the respondents who engaged in less severe suicidal behaviour; 0 otherwise. Therefore, two models were estimated. Model 1 referred to severe suicidal behaviour. Model 2 referred to less severe suicidal behaviour. This can be expressed as:

$$
p_{i}= \begin{cases}\operatorname{Pr}\left(y_{i}=1 \mid x_{i}\right) & \text { if } y_{i}=1 \text { is observed } \\ 1-\operatorname{Pr}\left(y_{i}=1 \mid x_{i}\right) & \text { if } y_{i}=0 \text { is observed }\end{cases}
$$

where $p_{i}$ is the probability of observing the value of $y_{i} ; \operatorname{Pr}\left(y_{i}=1 \mid x_{i}\right)$ is the probability of engaging in severe or less severe suicidal behaviour conditional on $x_{i}$, whereas $1-\operatorname{Pr}\left(y_{i}\right.$ $\left.=1 \mid x_{i}\right)$ is the probability of not engaging in severe or less severe suicidal behaviour. Hence, the models for severe and less severe suicidal behaviours can be expressed as:

$$
\operatorname{Pr}\left(y_{i}=1 \mid x_{i}\right)=\beta_{0}+\beta_{1} x_{i 1}+\beta_{2} x_{i 2}+\beta_{3} x_{i 3}+\cdots+\beta_{15} x_{i 15}
$$

where $x_{1}=$ income; $x_{2}=$ age; $x_{3}=$ family size; $x_{4}=$ male; $x_{5}=$ Malay; $x_{6}=$ Chinese; $x_{7}=$ tertiary-level education; $x_{8}=$ secondary-level education; $x_{9}=$ married; $x_{10}=$ physically active; $x_{11}=$ smoker; $x_{12}=$ self-rated good health; $x_{13}=$ self-rated fair health; $x_{14}=$ being diagnosed with diabetes; and $x_{15}=$ being diagnosed with hypercholesterolemia. The coefficient $\beta_{0}$ is the constant, which is the probability of engaging in severe or less severe suicidal behaviour when each $x$ is zero; and $\beta_{\mathrm{k}}$ is the coefficient which measures the change of the probability of engaging in severe or less severe suicidal behaviour when $x_{\mathrm{k}}$ increases by one unit.

Because of the non-linear nature of $E(y \mid x)$, maximum likelihood estimation (MLE) is used to estimate the models. To obtain the maximum likelihood estimator, the likelihood function is constructed as:

$$
L(\boldsymbol{\beta})=\prod_{y=1} F\left(\mathbf{x}_{\mathbf{i}} \boldsymbol{\beta}\right) \prod_{y=0}\left[1-F\left(\mathbf{x}_{\mathbf{i}} \boldsymbol{\beta}\right)\right]
$$

where $\mathbf{x}_{i} \boldsymbol{\beta}$ refers to $\beta_{0}+\beta_{1} x_{i 1}+\ldots$ Adding natural log $(\ln )$ into equation (3), the loglikelihood function is obtained and can be written as:

$$
\ln L(\boldsymbol{\beta})=\sum_{y=1} F\left(\mathbf{x}_{\mathbf{i}} \boldsymbol{\beta}\right)+\sum_{y=0}\left[1-F\left(\mathbf{x}_{\mathbf{i}} \boldsymbol{\beta}\right)\right]
$$

where $F(\cdot)$ lies between zero and one. Assuming $F(\cdot)$ is the standard logistic distribution, we use logit model for analysis. This model ensures that the probability of engaging in severe or less severe suicidal behaviour lies between zero and one for all the parameters. Also, a non-linear relationship between a probability and the explanatory variables is guaranteed. See Wooldridge (2013) for further discussion on logit model.

\section{Results}

The summary statistics of explanatory variables are presented in Table 1 . Of the total respondents, 1.9 percent engage in severe suicidal behaviour and 0.36 percent engage in less severe suicidal behaviour. The average monthly individual income, age and family size of the total respondents are RM1653.33, 41 years and four members, 
Table 1. Summary statistics of explanatory variables

\begin{tabular}{|c|c|c|c|c|}
\hline Variables & Mean / Percentage & Std. dev. & Minimum & Maximum \\
\hline Severe suicidal & 1.90 & - & - & - \\
\hline Less severe suicidal & 0.36 & - & - & - \\
\hline Income & 1653.33 & 2235.36 & 0 & 51000 \\
\hline Age & 41.18 & 15.41 & 18 & 101 \\
\hline Family & 4.41 & 2.236 & 1 & 15 \\
\hline Male & 46.11 & - & - & - \\
\hline Malay & 51.78 & - & - & - \\
\hline Chinese & 25.43 & - & - & - \\
\hline Tertiary & 26.39 & - & - & - \\
\hline Secondary & 47.52 & - & - & - \\
\hline Married & 68.21 & - & - & - \\
\hline Physical activity & 61.38 & - & - & - \\
\hline Smoking & 21.20 & - & - & - \\
\hline Good & 79.99 & - & - & - \\
\hline Fair & 18.17 & - & - & - \\
\hline Diabetes & 17.72 & - & - & - \\
\hline Cholesterol & 38.05 & - & - & - \\
\hline Observations & \multicolumn{4}{|c|}{10141} \\
\hline
\end{tabular}

Note: " For continuous variables, the entries refer to mean. For categorical variables, the entries refer to percentage.

Source: NHMS 2011.

respectively. Less than half of the respondents are males (46 percent). The majority of the respondents are Malays (52 percent), followed by Chinese ( 25 percent) and Indians/ others (23 percent). The education breakdown consists of 26 percent, 48 percent and 26 percent individuals with tertiary-, secondary- and primary-level education, respectively. A large proportion of the respondents are married (68 percent). In terms of lifestyle variables, 61 percent of the respondents are physically active and 21 percent are smokers. The majority of the respondents self-rate their health as good ( 80 percent), followed by those with self-rated fair (18 percent) and poor health ( 2 percent). Only a small proportion of individuals are diagnosed with diabetes (18 percent) and hypercholesterolemia (38 percent).

The results of Model 1 and Model 2 are illustrated in Tables 2 and 3, respectively. Before interpreting the specific results of each explanatory variable, the goodness-of-fit of each model is discussed. Four things are worthy of note. First, a large proportion of the outcomes are correctly predicted by Model 1 ( 98.10 percent) and Model 2 (99.60 percent). Second, the value of likelihood ratio is significant in Model 1, indicating that all the explanatory variables are jointly significant in affecting the likelihood of engaging in severe suicidal behaviour. Third, the $p$-values of Hosmer-Lemeshow in both models are not less than 5 percent, and this suggests that the models are not poor fit. Fourth, the constant term is insignificant in Model 1 , thus omitted variable bias may not be an issue in Model 1. 
Estimates of logit model are unable to be interpreted directly because they are obtained from the MLE, instead of least squares. Hence, the marginal effect of each explanatory variable in Models 1 and 2 is calculated. The purpose is to acquire a better understanding of the impacts of the explanatory variables on the likelihood of engaging in severe and less severe suicidal behaviours.

It is surprising to find that income is not significantly associated with suicidal behaviour, which rejects our hypothesis. Previous studies conducted elsewhere constantly show that suicide depends on income, but our findings suggest otherwise. In terms of age, although its effect on suicidal behaviour is not large, it is highly significant. Specifically, an additional year of age reduces the probability of adopting severe suicidal behaviour by approximately 0.1 percent. This finding appears to be consistent with those of Casey et al. (2006) and Song and Lee (2016), as well as our expectation. There are two explanations for this finding. Firstly, older individuals face less stress from work and family responsibilities than younger individuals (Altimus \& Tersine, 1973). Second, older individuals put more emphasises on health compared with their younger counterparts.

Table 2. Correlates of severe suicidal behaviour to sociodemographic, lifestyle and health factors

\begin{tabular}{|c|c|c|c|c|}
\hline Variables & $\begin{array}{l}\text { Estimated } \\
\text { coefficients }\end{array}$ & $\begin{array}{l}\text { Standard } \\
\text { errors }^{\mathrm{a}}\end{array}$ & $\begin{array}{l}\text { Marginal } \\
\text { effect }\end{array}$ & $\begin{array}{c}\text { Standard } \\
\text { errors }^{\mathrm{b}}\end{array}$ \\
\hline Constant & -0.279 & 0.446 & - & - \\
\hline Income & -0.001 & 0.001 & -0.001 & 0.001 \\
\hline Age & $-0.023 * * *$ & 0.006 & $-0.001 * * *$ & 0.001 \\
\hline Family & -0.034 & 0.033 & -0.001 & 0.001 \\
\hline Male & $-0.346^{*}$ & 0.188 & $-0.005^{*}$ & 0.003 \\
\hline Malay & $-0.634 * * *$ & 0.175 & $-0.010 * * *$ & 0.003 \\
\hline Chinese & $-0.403^{*}$ & 0.207 & $-0.005^{* *}$ & 0.003 \\
\hline Tertiary & -0.281 & 0.253 & -0.004 & 0.003 \\
\hline Secondary & -0.200 & 0.197 & -0.003 & 0.003 \\
\hline Married & $-0.540 * * *$ & 0.161 & $-0.009 * * *$ & 0.003 \\
\hline Physical activity & 0.138 & 0.156 & 0.002 & 0.002 \\
\hline Smoking & 0.069 & 0.230 & 0.001 & 0.004 \\
\hline Good & $-1.977 * * *$ & 0.268 & $-0.059 * * *$ & 0.014 \\
\hline Fair & $-1.517 * * *$ & 0.293 & $-0.015 * * *$ & 0.002 \\
\hline Diabetes & $0.414 * *$ & 0.195 & $0.007^{*}$ & 0.004 \\
\hline Cholesterol & $0.285^{*}$ & 0.160 & $0.004^{*}$ & 0.003 \\
\hline Likelihood ratio & \multicolumn{4}{|c|}{$106.030 * * *$} \\
\hline Hosmer-Lemeshow & \multicolumn{4}{|c|}{$17.290 *$} \\
\hline Correct prediction (\%) & \multicolumn{4}{|c|}{98.100} \\
\hline Observations & \multicolumn{4}{|c|}{10141} \\
\hline
\end{tabular}

Note: ${ }^{a}$ Standard errors for estimated coefficients. ${ }^{b}$ Standard errors for marginal effects. $* * *$ significant at the $1 \%$ level, ${ }^{* *}$ significant at the $5 \%$ level and * significant at the $10 \%$ level. Source: NHMS 2011. 
Table 3. Correlates of less severe suicidal behaviour to sociodemographic, lifestyle and health factors

\begin{tabular}{|c|c|c|c|c|}
\hline Variables & $\begin{array}{l}\text { Estimated } \\
\text { coefficients }\end{array}$ & $\begin{array}{c}\text { Standard } \\
\text { errors }^{\mathrm{a}}\end{array}$ & $\begin{array}{c}\text { Marginal } \\
\text { effect }\end{array}$ & $\begin{array}{l}\text { Standard } \\
\text { errors }^{\mathrm{b}}\end{array}$ \\
\hline Constant & $-3.476 * * *$ & 1.300 & - & - \\
\hline Income & -0.001 & 0.001 & -0.001 & 0.001 \\
\hline Age & -0.014 & 0.014 & -0.001 & 0.001 \\
\hline Family & -0.010 & 0.072 & -0.001 & 0.001 \\
\hline Male & -0.154 & 0.405 & -0.001 & 0.001 \\
\hline Malay & $-0.809 * *$ & 0.385 & $-0.003 * *$ & 0.001 \\
\hline Chinese & $-0.798^{*}$ & 0.477 & $-0.002^{*}$ & 0.001 \\
\hline Tertiary & -0.197 & 0.550 & -0.001 & 0.001 \\
\hline Secondary & -0.150 & 0.454 & -0.001 & 0.001 \\
\hline Married & $-0.706 * *$ & 0.359 & $-0.002 * *$ & 0.001 \\
\hline Physical activity & -0.094 & 0.344 & -0.001 & 0.001 \\
\hline Smoking & -0.086 & 0.503 & -0.001 & 0.001 \\
\hline Good & -0.429 & 1.030 & -0.001 & 0.004 \\
\hline Fair & -0.162 & 1.069 & -0.001 & 0.003 \\
\hline Diabetes & -0.409 & 0.557 & -0.001 & 0.001 \\
\hline Cholesterol & 0.244 & 0.363 & 0.001 & 0.001 \\
\hline Likelihood ratio & \multicolumn{4}{|c|}{14.840} \\
\hline Hosmer-Lemeshow & \multicolumn{4}{|c|}{$16.000 *$} \\
\hline Correct prediction (\%) & \multicolumn{4}{|c|}{99.600} \\
\hline Observations & \multicolumn{4}{|c|}{10141} \\
\hline
\end{tabular}

Note: $\quad$ a Standard errors for estimated coefficients. ${ }^{\mathrm{b}}$ Standard errors for marginal effects. ${ }^{* * *}$ significant at the $1 \%$ level, ${ }^{* *}$ significant at the $5 \%$ level and ${ }^{*}$ significant at the $10 \%$ level. Source: NHMS 2011.

As anticipated, being male significantly reduces the likelihood of suicide. While the effect of gender on suicide is not highly significant, it should be given attention. We find that males are 0.5 percent less likely to engage in severe suicidal behaviour than females. Similar findings are evidenced by Neumayer (2003b) and Qin et al. (2003). In terms of ethnicity, the finding is in agreement with our hypothesis and the results of Morris and Maniam (2001) that Indians have the highest likelihood committing suicide. As the estimated results show, Malays and Chinese have 0.3-1 percent and 0.2-0.5 percent lower probabilities of engaging in severe and less severe suicidal behaviours, respectively, compared with Indian/others. Based on this finding, we conclude that religion and culture can affect individuals' perspective on suicide. However, a qualitative study needs to be conducted in order to gain a more in-depth understanding of how ethnicity and religion affect suicide. Inclusion of religion as a separate variable in the regression can also be considered in future studies. The purpose is to control for the effect of religion on suicidal behaviour. 
Another finding that contradicts the evidences of previous studies is the effect of education (Li et al., 2011; Song \& Lee, 2016). We find that there is no significant relationship between education and suicidal behaviour. This finding is somewhat unexpected because we assume that education can affect the likelihood of engaging in suicidal behaviour. With data availability, future studies may want to include education as a continuous variable to allow for a linear relationship. The effect of marital status on suicidal behaviour is worthy of note. We find that married individuals are $0.2-$ 0.9 percent less likely to engage in severe and less severe suicidal behaviours than unmarried individuals. This finding is consistent with those of Neumayer (2003a), as well as our hypothesis. The argument is simple. Since loneliness and lack of support from spouses will reduce the connectedness, unmarried individuals are less likely to value their life compared to their married counterparts.

Even though the lifestyle variables do not have significant effects on suicidal behaviour, we find that health variables are significantly associated with suicidal behaviour. Consistent with our anticipation as well as the findings of Qin et al. (2003) and Vilhjalmsson et al. (1998), our results show that having good health condition reduces the propensity to engage in suicidal behaviour. Specifically, we find that individuals who self-rate their health as good and fair have 5.9 percent and 1.5 percent lower likelihoods of engaging in severe suicidal behaviour, respectively, compared to individuals who self-rate their health as poor. In addition, we also find that individuals who have diabetes ( 0.7 percent) and hypercholesterolemia ( 0.4 percent) are more likely to adopt severe suicidal behaviour than their healthy counterparts.

\section{Conclusion}

In light of the spike in suicide rate, we make an effort to examine the determinants of suicidal behaviour among adults in Malaysia, which is a topic that previous studies seldom focus on. Using a nationally representative data and rigorous statistical method, we find that sociodemographic (age, gender, ethnicity and marital status) and health factors (self-rated health, diabetes and hypercholesterolemia) are able to affect the likelihood of engaging in suicidal behaviours. Most of the results are consistent with our hypotheses, as well as the findings of previous studies. We find that when individuals grow older, their tendency to engage in suicidal behaviour reduces. Being female and Indian/others are positively associated with suicidal behaviour. Married adults have a lower probability of adopting suicidal behaviour than unmarried adults. In terms of health factors, self-rated poor health, and being diagnosed with diabetes and hypercholesterolemia increase the likelihood of engaging in suicidal behaviour.

Our findings have important implications for policy. Firstly, an intervention measure directed towards females may yield promising outcomes. Policy makers should figure out appropriate methods that can help to reduce the stress among females if the goal of reducing the prevalence of suicide is to be achieved. Secondly, government should make a concerted effort to change the perspective on suicide among Indians. Inviting someone who has high influential power, such as Hindu spokesperson to give talks about the topic on suicide is desirable. Third, a policy that can provide unmarried 
individuals with social support and encourage marriage among single adults is worthy of consideration. However, this policy should be implemented carefully as it may cause problems of early marriage. Lastly, a nationwide health promotion programme should be introduced. Since poor health condition can lead to suicide, a programme that can improve population health may indirectly reduce the suicide rate.

In spite of the fact that our study has important contributions to literature and policy, several limitations are acknowledged. First, all the information used in our study is self-reported. Hence, reliability may be an issue. Second, the causality between outcome and explanatory variables is unable to be well-identified because our analyses are based on cross-sectional data. Third, owing to secondary analysis of the data, some important variables that may affect suicidal behaviour, such as employment status, consumption of drugs and peer influence are not taken into account. Future studies are suggested to consider using a panel data to investigate changes in the determining factors of suicidal behaviour over time. In addition, how suicide affects well-being can also be considered in future studies.

\section{References}

Aishvarya, S., Maniam, T., Sidi, H., \& Oei, T.P.S. (2014). Suicide ideation and intent in Malaysia: A review of the literature. Comprehensive Psychiatry, 55(S1), S95-S100. https://doi. org/10.1016/j.comppsych.2013.01.005

Altimus, C.A., \& Tersine, R.J. (1973). Chronological age and job satisfaction: The young blue collar worker. Academy of Management Journal, 16(1), 53-66.

Bahar, N., Ismail, W.S.W., Hussain, N., Haniff, J., Bujang, M.A., Hamid, A.M., ... Hayati, N. (2015). Suicide among the youth in Malaysia: What do we know? Asia-Pacific Psychiatry, 7(2), 223229. https://doi.org/10.1111/appy.12162

Becker, G.S. \& Murphy, K.M. (1988). A theory of rational addiction. Journal of Political Economy, 96(4), 675-700.

Casey, P.R., Dunn, G., Kelly, B.D., Birkbeck, G., Dalgard, O.S., Lehtinen, V., ... Dowrick, C. (2006). Factors associated with suicidal ideation in the general population. British Journal of Psychiatry, 189(5), 410-415. https://doi.org/10.1192/bjp.bp.105.017368

Cheah, Y.K. (2012). An exploratory study on self-rated health status: The case of Penang, Malaysia. Malaysian Journal of Economic Studies, 49(2), 141-155.

Cheah, Y.K. (2018). The utilization of diagnostic tests among the elderly: Evidence from Malaysia. Socio-Economic Planning Sciences, 62(June), 121-128. https://doi.org/10.1016/j. seps.2017.10.002

Cheah, Y.K., Azahadi, M., Phang, S.N., \& Abd Manaf, N.H. (2017). The income elasticity of participation in physical activity: Evidence from Malaysia. International Journal of Economics and Management, 11(2), 321-334.

Hendin, H., Vijayuakumar, L., Bertolote, J.M., Wang, H., Phillips, M.R., \& Pirkis, J. (2008). Epidemiology of suicide in Asia. In H. Hendin, M.R. Philips, L. Vijayakumar, J. Pirkis, H. Wang, P. Yip, D. Wasserman, J.M. Bertolote \& A. Fleischmann (Eds.), Suicide and suicide prevention in Asia (pp. 7-18). Geneva: World Health Organization.

Institute for Public Health. (2011). National health and morbidity survey 2011: Non-communicable diseases. Putrajaya: Ministry of Health Malaysia.

Klonsky, D. \& May, A. M. (2015). The three-step theory (3ST): A new theory of suicide rooted in the "Ideation-to-Action" framework. International Journal of Cognitive Therapy, 8(2), 114129. https://doi.org/10.1521/ijct.2015.8.2.114. 
Kolves, K., Milner, A., \& Varnik, P. (2013). Suicide rates and socioeconomic factors in Eastern European countries after the collapse of the Soviet Union: Trends between 1990 and 2008. Sociology of Health and IIIness, 35(6), 956-970. https://doi.org/10.1111/1467-9566.12011

Li, Y., Li, Y., \& Cao, J. (2012). Factors associated with suicidal behaviors in mainland China: A metaanalysis. BMC Public Health, 12(524), 1-13. https://doi.org/10.1186/1471-2458-12-524

Li, Z., Page, A., Martin, G., \& Taylor, R. (2011). Attributable risk of psychiatric and socio-economic factors for suicide from individual-level, population-based studies: A systematic review. Social Science and Medicine, 72(4), 608-616. https://doi.org/10.1016/j.socscimed.2010.11.008

Morris, P., \& Maniam, T. (2001). Ethnicity and suicidal behaviour in Malaysia: A review of the literature. Transcultural Psychiatry, 38(1), 51-63. https://doi.org/10.1177/136346150103800105

Neumayer, E. (2003a). Are socioeconomic factors valid determinants of suicide? Controlling for national cultures of suicide with fixed-effects estimation. Cross-Cultural Research, 37(3), 307329. https://doi.org/10.1177/1069397103253708

Neumayer, E. (2003b). Socioeconomic factors and suicide rates at large-unit aggregate levels: A comment. Urban Studies, 4O(13), 2769-2776. https://doi.org/10.1080/0042098032000191029

Purselle, D.C., Heninger, M., Hanzlick, R., \& Garlow, S.J. (2009). Differential association of socioeconomic status in ethnic and age-defined suicides. Psychiatry Research, 167(3), 258265. https://doi.org/10.1016/j.psychres.2008.02.003

Qin, P., Agerbo, E., \& Mortensen, P.B. (2003). Suicide risk in relation to socioeconomic, demographic, psychiatric, and familial factors: A national register-based study of all suicides in Denmark, 1981-1997. American Journal of Psychiatry, 160(4), 765-772. https://doi. org/10.1176/appi.ajp.160.4.765

Rehkopf, D.H., \& Buka, S.L. (2006). The association between suicide and the socio-economic characteristics of geographical areas: A systematic review. Psychological Medicine, 36(2), 145-157. https://doi.org/10.1017/S003329170500588X

Sipalan, J. (2012, June 5). Suicide rate on the rise in Malaysia. The Star Online. Retrieved from http://www.thestar.com.my/news/nation/2012/06/05/suicide-rate-on-the-rise-in-malaysia/

Song, H.B., \& Lee, S-A. (2016). Socioeconomic and lifestyle factors as risks for suicidal behaviour among Korean adults. Journal of Affective Disorders, 197(June), 21-28. https://doi. org/10.1016/j.jad.2016.02.035

Sunip, A. (2015, October 11). Suicide cases in Malaysia could increase, warns psychiatrist. The Rakyat Post. Retrieved from http://www.therakyatpost.com/news/2015/10/11/suicide-casesin-malaysia-could-increase-warns-psychiatrist/

Vilhjalmsson, R., Kristjansdottir, G., \& Sveinbjarnardottir, E. (1998). Factors associated with suicide ideation in adults. Social Psychiatry and Psychiatric Epidemiology, 33(3), 97-103. https://doi. org/10.1007/s001270050028

Wooldridge, J. (2013). Introductory econometrics: A modern approach (5th ed.). Ohio: SouthWestern Cengage Learning.

World Health Organization. (2016). Fact sheet: Suicide. Retrieved from http://www.who.int/ mediacentre/factsheets/fs398/en/

World Health Organization. (2010). Global recommendations on physical activity for health. Geneva: Author.

Ying, Y.H., \& Chang, K. (2009). A study of suicide and socioeconomic factors. Suicide and LifeThreatening Behavior, 39(2), 214-226. https://doi.org/10.1521/suli.2009.39.2.214 
